Article

\title{
Acoustical Renovation of University Multipurpose Halls: The Case of Lala Mustafa Paşa Hall
}

\author{
Halil Zafer Alibaba ${ }^{1, *(1)}$ and Mesut B. Ozdeniz ${ }^{2}$ \\ 1 Faculty of Architecture, Department of Architecture, Eastern Mediterranean University, via Mersin 10, \\ Famagusta 99628, Northern Cyprus, Turkey \\ 2 Faculty of Architecture, Department of Architecture, European University of Lefke, via Mersin 10, \\ Gemikonağ1 99800, Northern Cyprus, Turkey; mesut.ozdeniz@gmail.com \\ * Correspondence: halil.alibaba@emu.edu.tr; Tel.: +90-533-863-0881
}

Received: 22 January 2019; Accepted: 2 March 2019; Published: 6 March 2019

check for updates

\begin{abstract}
Eastern Mediterranean University's Lala Mustafa Paşa hall is a multipurpose auditorium with conflicting functions. It is used for lectures, graduation ceremonies, music performances, shows, and sports. Thus, it is necessary to provide both speech intelligibility and quality sound. Many complaints were made regarding the long reverberation and echoes in the hall. To find the optimum solution for all of these conflicting uses, a survey of the acoustic parameters for music and speech was conducted, the criteria for which were identified. Measurements of these parameters were taken for the unoccupied hall. It was found that the acoustic conditions for both speech and music were in a critical condition in the hall. A simulation program was used to find a suitable solution, and various solutions were tested. The optimum solution was found to be the use of fireproof pyramidal melamine plates on the ceiling, and melamine plates with fireproof textile on the front surface with an air cavity on the walls at the rear. The long sidewalls at various levels on the tribunes were kept untreated. These measures satisfy the criteria for both music and speech without disrupting the sports activities.
\end{abstract}

Keywords: room acoustics; multi-purpose hall; acoustical simulation; reverberation time; speech intelligibility

\section{Introduction}

Eastern Mediterranean University's indoor sports hall, Lala Mustafa Paşa, is used as a multipurpose auditorium. It is not only used as an indoor sports hall, but also as a lecture hall, for graduation ceremonies, and for some music performances and shows. Thus, it is necessary to provide both speech intelligibility and quality sound. In addition to using the building for conferences and music there is the complication of the need to use both amplified and unamplified music. In view of the complaints that were received about the poor quality of sound, it was considered to be important to find the optimum solution for these conflicting uses.

Lala Mustafa Paşa sports hall has a total playing and spectator area of $3120 \mathrm{~m}^{2}$. The distance between the two side walls behind the tribunes is $65 \mathrm{~m}$, and the distance behind the other two end walls is $48 \mathrm{~m}$. The height from the play area to the ceiling is $19 \mathrm{~m}$, and the internal volume is approximately $38,000 \mathrm{~m}^{3}$. The building is a reinforced concrete skeleton structure with the roof spanned with a flat-space frame steel structure and covered with aluminum sandwich panels as seen in Figures 1 and 2. 


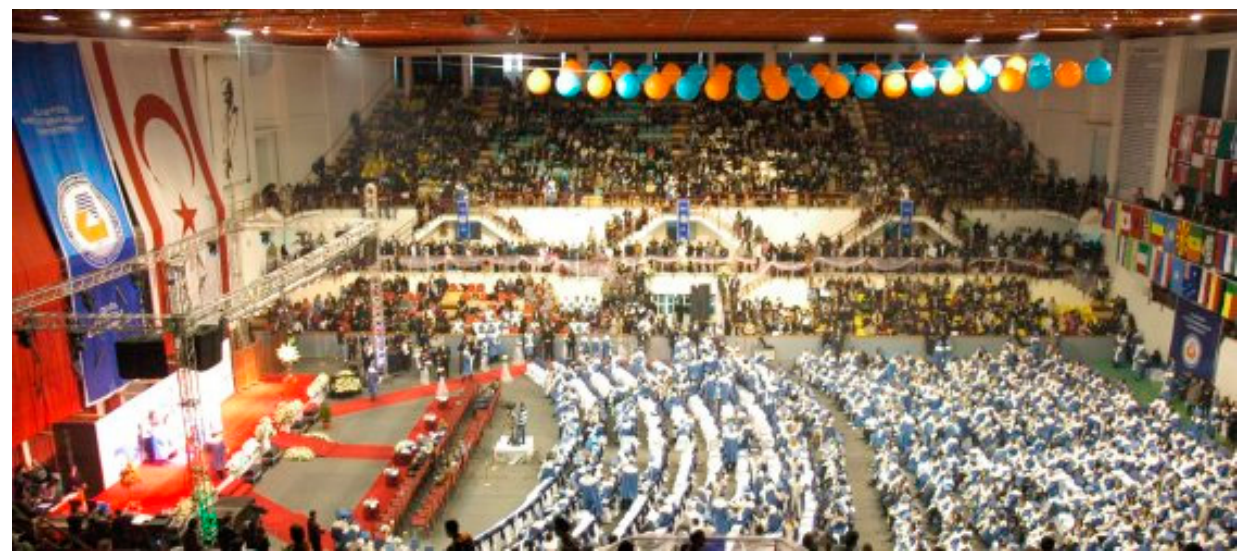

Figure 1. Internal view of the hall during a graduation ceremony.

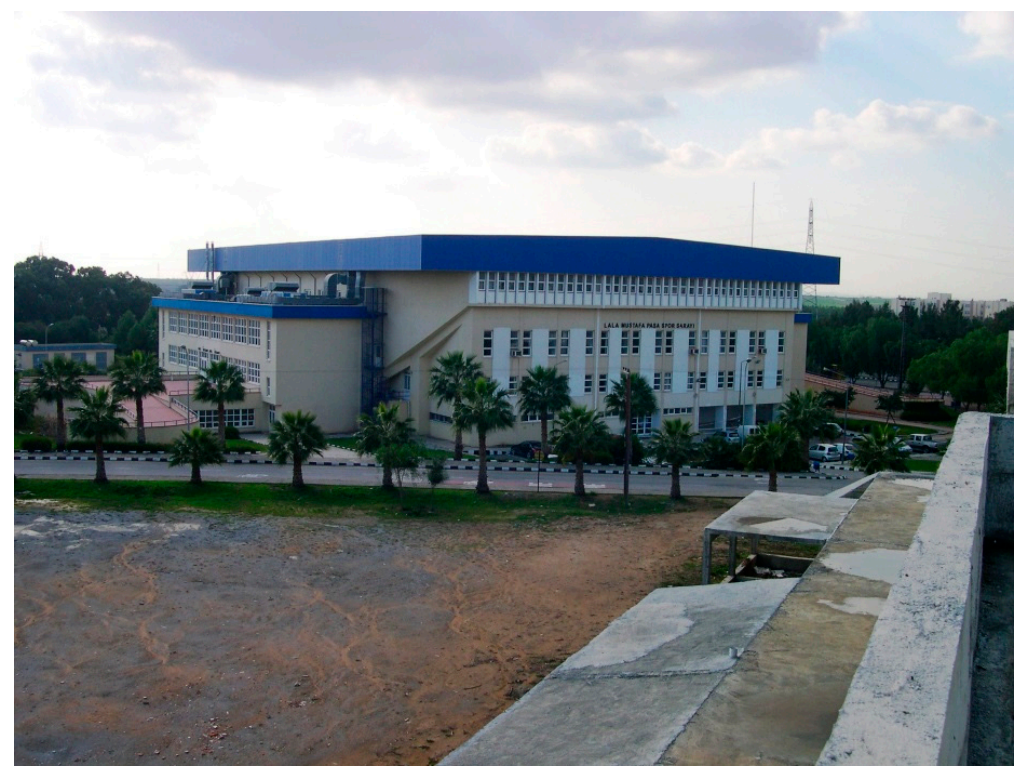

Figure 2. Exterior view of the hall.

Auditoria are rarely designed as single use spaces, and are more commonly used for speeches, music, theatre, performances, and fashion shows [1]. In historical interiors with curved walls, sound can slide off, so that two people can hear each other easily without the need for an amplification system [2]; modern structures often do not have curved walls. This case study seeks to address some of these issues.

\section{Literature Review}

There has been a lot of research about auditorium acoustics, which helps us to both solve acoustic problems and to design better auditoria. In this section, the authors evaluate some of the works published during the last fifteen years. A long reverberation time is necessary in large halls for many musical activities, but this carries risks for speech [3]. The longer reverberation time issue can be solved via absorbent materials, although these materials may reduce the sound level, which causes risks for a lower reverberation time. Porous materials can be used for mid frequencies but are not good for low frequencies [1]. It has been observed that in some auditoria, the reverberation time is longer than it should be, causing a horizontal reverberant field to occur at ceiling level [4]. In order to improve hearing conditions on the stage, covering the rear wall with an absorbent curtain will stop echoes [5], and adding a pause of $200 \mathrm{~ms}$ between words will also avoid an echo and improve intelligibility for those with impaired hearing [6]. 
Brunskog et al. [7] investigated how to increase voice level and speaker comfort in speech halls. In speech auditoria, it is necessary to direct the sounds towards the middle and back seats of the auditorium. In music auditoriums, it is necessary to diffuse the sounds, although some reflection from the two sides of the seats is also needed. Thus, there should be a balance between the diffused and reflected sound. Moreover, improving ceiling shape and adding absorbent materials to the rear wall surfaces will reduce reverberation time to optimal levels and will increase early reflections by eliminating shadow zones. Improvements in window insulation may decrease noise levels by $20 \mathrm{~dB}$ for improved speech intelligibility [8].

Beranek [9] conducted a study on the subjective parameters of fifty-eight concert halls and showed the importance of these new parameters. In a relatively recent article, he carried out an appraisal of concert hall acoustics [10]. Hyde [11] studied acoustical intimacy in concert halls and showed how to achieve this in concert hall design.

Kwon and Siebein [12] carried out a chronological study on the acoustical indices in music performance halls [1,3]. There have been a number of reports on the renovation of existing auditoriums [13-15]. However, there is little research on multi-purpose auditoria used for music, speech, and sports. In such auditoria, it is not possible to use diffusers and reflectors in a conventional way.

In education, the reverberation time, speech transmission index, and background noise have major impacts on acoustic quality [16-18]. However, acoustical issues for coaches deal with interior noise because of side wall vibration, back area noise, and floor sound transmission loss [19].

\section{Method of the Study}

\subsection{Measuring Method}

The measurements were carried out when the hall was unoccupied. A Bruel \& Kjaer sound level meter and analyzer type 2250, DIRAC room acoustics software type 7841 [20], omnipower omnidirectional sound source, and a power amplifier with a receiver and transmitter were used. The position of the source and twenty measurement points are shown in Figure 3. The layout of the measurement system is given in Figure 4.

DIRAC is capable of producing internal noise of various types and analyzing the impulse responses of the room by the use of a PC, a sound device, and microphones at heights of $1 \mathrm{~m}$, $3.5 \mathrm{~m}, 5.5 \mathrm{~m}$, and $7.5 \mathrm{~m}$, as shown in Figure 3. In this study, Maximum-Length Sequence (MLS) was used as an alternative to the conventional white noise. The noise was produced in the room by the omnidirectional loud speaker through a power amplifier at a hieght of $1.5 \mathrm{~m}$. DIRAC then calculated the frequency spectrum and many other acoustical parameters, such as reverberation time, early decay time (EDT), clarity (C80), definition (D50), and speech intelligibility. Acoustical parameters were determined according to the ISO 3382-1 and BS EN 60268-16 standards [21,22].

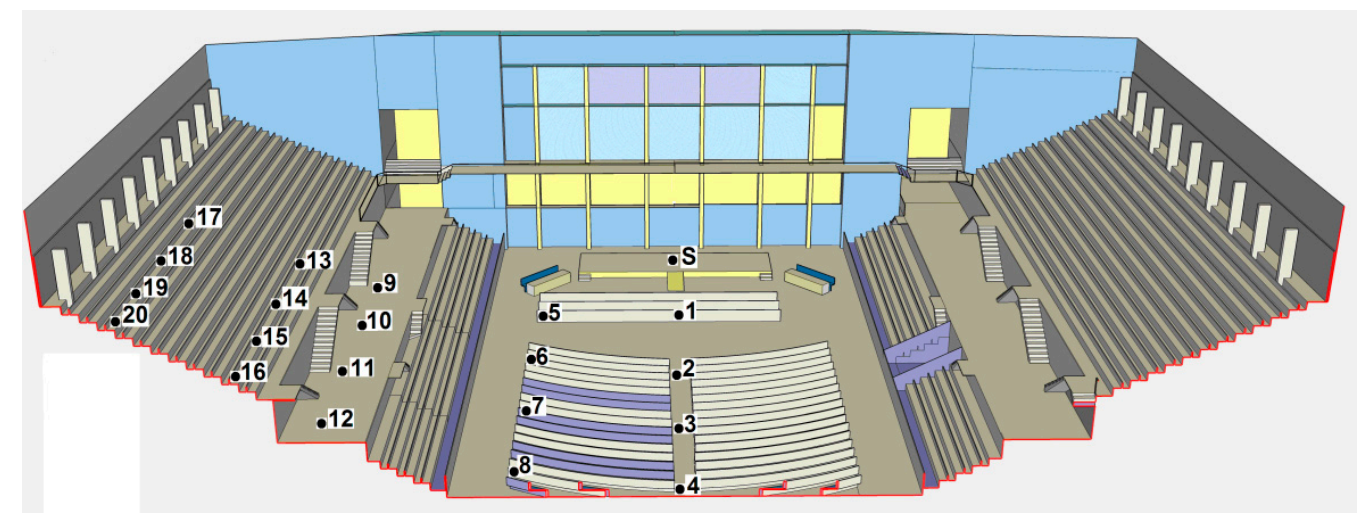

Figure 3. Perspective of the hall. 


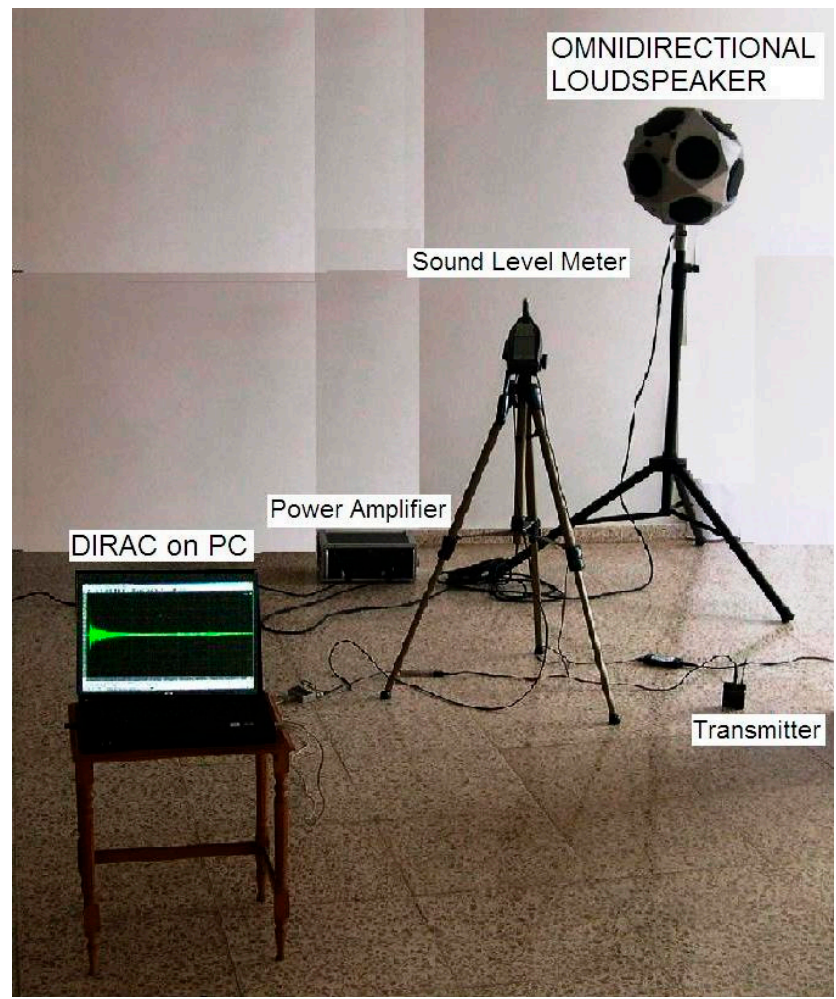

Figure 4. Picture of the measurement setup.

There are a number of objective and subjective parameters to judge the acoustic performance of a hall. The research has shown that some of these parameters have lost their importance. Generally, the most important objective room acoustic parameter is the reverberation time (RT). This is the time needed to achieve a $60 \mathrm{~dB}$ level decay after sound emission is interrupted. It gives fullness and a pleasant tone to music but must not be so great as to destroy voice intelligibility. While it is a very important parameter of room acoustics, it is not the only one. The relationship between a sound falling and the time needed from when the sound source is turned off is not linear. Thus, it is necessary to find the slope of the fall such as T10, T15, T20, and T30 and convert it to a reverberation time of $60 \mathrm{~dB}$. T10 is the reverberation time found by the slope of a fall between -5 to $-15 \mathrm{~dB}, \mathrm{~T} 15$ is the reverberation time found by the slope of a fall between -5 to $-20 \mathrm{~dB}$ and so on. Besides finding the reverberation time by T10, T15, T20, and T30, it is also necessary to find the best reverberation time, designated as the RT.

The early decay time (EDT) is the initial portion of the sound decay curve of the reverberation time. Kuttruff [23] has shown that EDT is responsible for our subjective impression of reverberation. It affects the auditorium's support of voices and adds definition to the higher tones of music. Similar to $\mathrm{RT}$, if it is too high, it reduces intelligibility. RT is determined from the first $10 \mathrm{~dB}$ range of the decay curve. From the corresponding slope, the EDT is calculated as the time to reach $-60 \mathrm{~dB}$. EDT is also the parameter that relates best to speech intelligibility reduction.

The clarity (C80) is the logarithmic early-to-late arriving sound energy ratio, where "early" means "during the first $80 \mathrm{~ms}$ " and "late" means "after the first $80 \mathrm{~ms}$ ". It characterizes the separation in time of sounds generated by individual instruments or groups of instruments. It should be appropriate to enable musical detail to be appreciated.

The definition (D50) is used for speech signals and it is the early-to-total arriving sound energy ratio, where "early" means "during the first $50 \mathrm{~ms}$ ". The Definition is also called "Deutlichkeit". There is a good relation between definition and speech intelligibility and definition is expressed as a percentage.

In the design of music auditoria, there are other parameters that have to be considered, including: Intimacy, Spaciousness, Diffusion, Warmth, Brilliance, Reflecting Surfaces, Spatial Impression (SI), 
and Stage Support Factor (ST1) [24]. Intimacy exists if the music in an auditorium is heard the same as it is in small halls and if listeners feel as if they are in contact with the performers. In order to achieve this, the arrival time of the first reflection after the direct sound should be less than $25 \mathrm{~ms}$. Spaciousness is achieved if the sounds at listeners' seats include some early reflections from near lateral directions. Its measure, the inter-aural cross correlation coefficient (IACC), should exceed 0.6 [25]. This parameter, however, was not measured in this hall. Diffusion in an auditorium is provided by large and small irregularities on the walls, balcony parapets, and the ceiling to give the sound a rich patina. Warmth is the presence of strong low frequency or bass sounds in a hall. Brilliance is the presence of strong higher frequency or treble components. Spatial Impression (SI) is the feeling of being enveloped within the music. It is determined by differences in the signal received by each ear. Barron and Marshall [26] proposed an equation, for the degree of SI, based on Lateral Energy Fraction $\left(\mathrm{L}_{\mathrm{f}}\right)$ as: $\mathrm{SI}=14.5\left(\mathrm{~L}_{\mathrm{f}}-0.05\right)$.

Stage Support Factor (ST1) is a measure of the strength of the orchestral sound returned by nearby reflecting surfaces to the ears of each player in the orchestra pit. Beranek [10] argues that stage support factor (ST1) is very important for musicians, but since this is a multi-purpose hall, nothing could be done to provide stationary reflectors around the stage. In some good auditoriums, it was reported that the ST1 is lower than $-15 \mathrm{~dB}$.

Reverberation time for speech auditoria of around $38,000 \mathrm{~m}^{3}$ should be $1.35 \mathrm{~s}$, and for the music auditoria of the same size it should be $2.1 \mathrm{~s}$ for frequencies of $500 \mathrm{~Hz}$ and higher. For $125 \mathrm{~Hz}$, these values should be increased by a factor of 1.5 and by 1.15 for $250 \mathrm{~Hz}$ [27]. Since it is not practical to fit variable sound reflectors and absorbers to this hall, the authors adopted the optimum reverberation for the mid frequencies in the range of 1.6 to $1.8 \mathrm{~s}$ [28], 1.4 to $1.9 \mathrm{~s}$ for the early decay time, and a bass ratio greater than 1.0. [19]. Clarity (C80) should be between -2 to $+2 \mathrm{~dB}$ and values of definition (D50) in excess of 0.50 are considered satisfactory for speech intelligibility [29].

The other parameters for speech auditoria are the Speech Transmission Index (STI), Alcons, Room Acoustics Speech Transmission Index (RASTI), The modulation transfer function (MTF) describes to what extent modulation $\mathrm{m}$ is transferred from source to receiver, Articulation Index, Percentage Articulation Loss of Consonants, Signal-to-Noise Ratio (SNR), and Direct-to-Reverberant Ratio. In this study, only the STI and RASTI were considered because they are the newest parameters and can be derived by the use of DIRAC [20]. Speech Transmission Index (STI) is a measure of the speech intelligibility in a room and is judged as unintelligible between 0.0 to 0.3 , poor between 0.3 to 0.45 , fair between 0.45 to 0.6 , good between 0.6 to 0.75 , and excellent when $>0.75$. It can be measured separately for male and female voices. Whenever there is too much background noise, the Useful-to-Detrimental Index U50, suggested by Bradley [30], may be an alternative to STI. Room Acoustics Speech Transmission Index (RASTI) is another speech intelligibility index. It is the simplified version of STI. In order to make correct RASTI measurements, the overall system frequency response must be uniform from $125 \mathrm{~Hz}$ through the $8 \mathrm{kHz}$ octave band, the background noise must be smooth in time and frequency, the space must be substantially free of discrete echoes, and the reverberation time must not be too frequency-dependent [22]. The average RASTI for all the points of the hall was 0.3435 . Measurements of these parameters for a number of points are given in Table 1. The results show that except for points near the speaker, speech intelligibility is very poor.

The STIPA is a simplified version of the STI (speech transmission index), intended to emulate STI under conditions typical for public address systems. Since STI measurements were made with DIRAC [20], it was found that there was not much difference between STI and STIPA.

Impulse to noise ratio (INR) is defined as the logarithmic ratio of the maximum impulse response level and the noise level and reflects the decay range. This parameter is not a measure of room acoustics, however, it indicates whether the related measurements are correct. With good measurements, most practical INR values range from 35 to $45 \mathrm{~dB}$ [21]. The INR in Figure 5 shows that the measurements are reliable. 
Table 1. Measurement results of some speech intelligibility parameters. STI = speech transmission index; RASTI = room acoustics speech transmission index.

\begin{tabular}{cccc}
\hline Point & STI female & STI male & RASTI \\
\hline A1 & 0.49 (Fair) & 0.49 (Fair) & 0.43 (Poor) \\
A2 & 0.39 (Poor) & 0.39 (Poor) & 0.37 (Poor) \\
A3 & 0.38 (Poor) & 0.37 (Poor) & 0.36 (Poor) \\
A5 & 0.47 (Fair) & 0.47 (Fair) & 0.43 (Poor) \\
A9 & 0.45 (Fair) & 0.44 (Poor) & 0.43 (Poor) \\
A10 & 0.40 (Poor) & 0.40 (Poor) & 0.38 (Poor) \\
A20 & 0.35 (Poor) & 0.35 (Poor) & 0.33 (Poor) \\
\hline
\end{tabular}

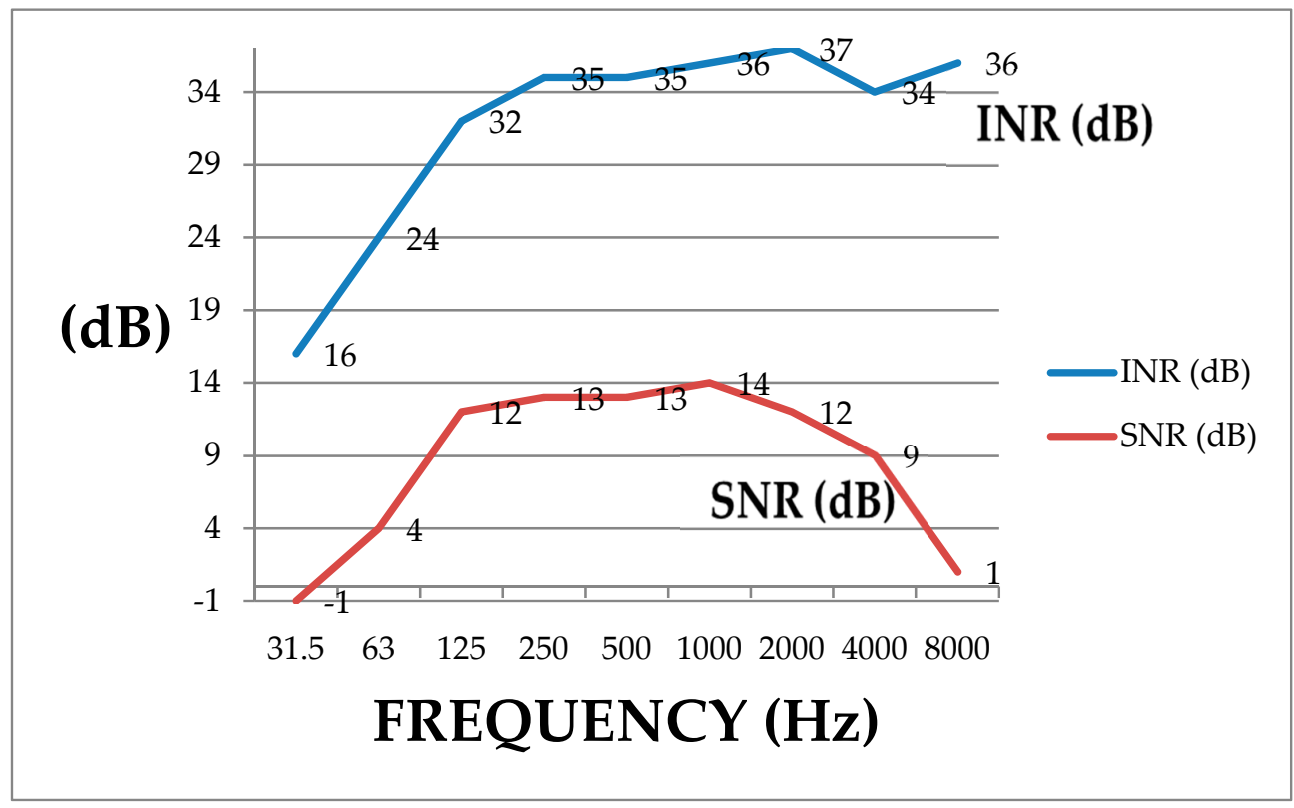

Figure 5. Average impulse-to-noise ratio (INR) and signal-to-noise ratio (SNR) of all the points in the hall.

Signal-to-noise ratio (SNR) is the signal of the speaker's voice in decibels, minus the background noise. If the SNR is large, speech intelligibility is greater. If the SNR is less than $10 \mathrm{~dB}$, speech intelligibility is degraded [31]. Figure 5 shows that the SNR of the unoccupied hall for low and very high frequencies was lower than $10 \mathrm{~dB}$. When the hall is occupied, it is expected to be lower than $10 \mathrm{~dB}$ for most of the frequencies.

The Bass Ratio (BR) or Bass Strength is an objective measure of warmth. It shows how low frequency (bass) sounds are perceived in a concert hall. This is simply the ratio of the low frequency to mid frequency reverberation times. Thus it can be expressed as: $\mathrm{RT}_{125 \mathrm{~Hz}+250 \mathrm{~Hz}} / \mathrm{RT}_{500 \mathrm{~Hz}+1000 \mathrm{~Hz}}$.

Most practical BR values range from 0.1 to 10. Bradley, Soulodre, and Norcross [32] give a very good interpretation of $B R$ and conclude that although the perceived strength of bass sounds is not influenced by the low frequency reverberation time, the levels of both the early- and late-arriving bass sounds influence the perceived strength of the bass sounds. The average Bass Ratio of all the points in the hall was measured as 0.94 . In both speech and music auditoriums, there should not be any echo or flutter echo, and the sound energy must be diffused homogenously all over the auditorium. The measurements were made at the hall when there were not any spectators. The results of the measurements are given in Figure 6.

In an auditorium, background noise is generated from the air conditioning, ventilation systems, machines, audience, traffic outside the building, and environmental causes like rain and thunder. It was important to measure the background noise level (BNL) for some of the parameters. If the BNL 
is high, the speaker may increase his/her voice to overcome the noise, although this may also cause mental pressure for the speaker. The background noise level (BNL) was measured as an Equivalent Continuous A-Weighted Sound Level when the hall was unoccupied but with the air conditioning system on; it was measured as $\mathrm{L}_{\mathrm{eq}}=42.4 \mathrm{~dB}(\mathrm{~A})$. It is very difficult to measure the background noise with the presence of spectators because it varies according to their level of attention. In another measurement, the hall was full with the spectators, the air conditioning system was on, and the spectators were asked for one minute of silence. The measured $\mathrm{L}_{\mathrm{eq}}$ was $50.0 \mathrm{~dB}(\mathrm{~A})$ during that time.

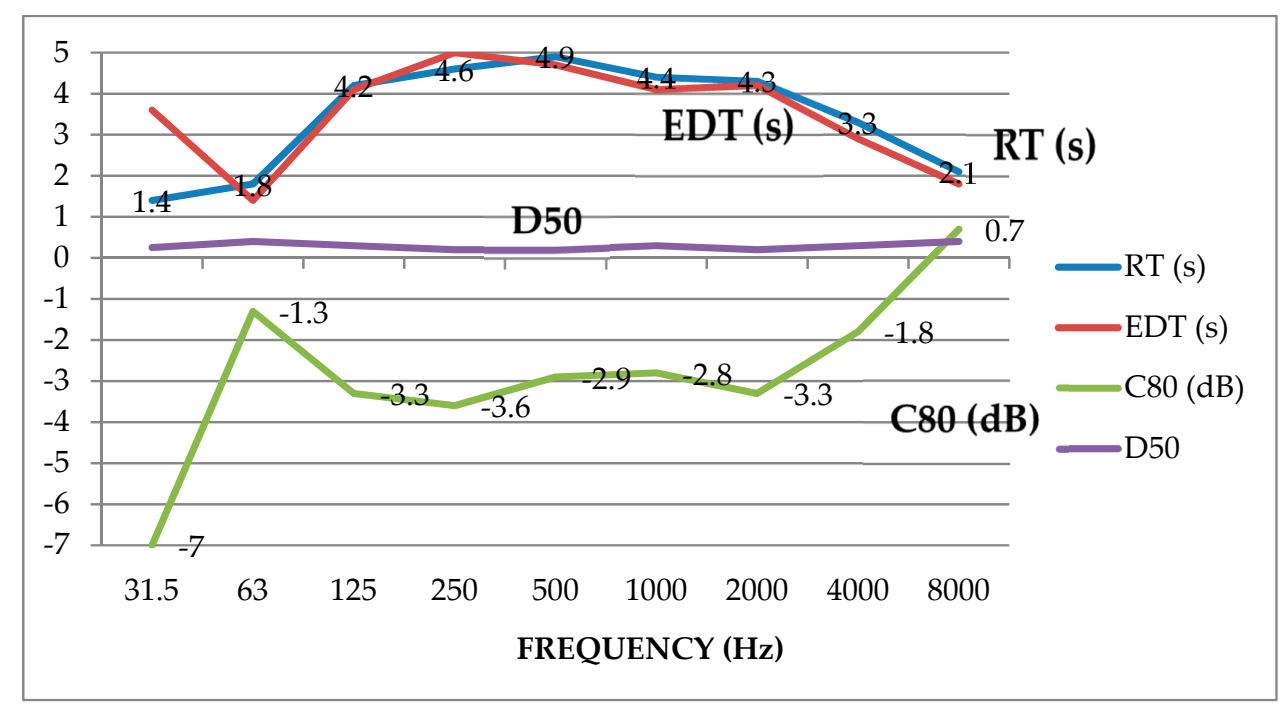

Figure 6. Average reverberation time (RT), early decay time (EDT), clarity (C80), and definition (D50) of all the points in the hall.

Discussion of the Measurement Results

Since this is a multipurpose hall, the parameters related to both music and speech were considered. It can be seen from Figure 6 that for frequencies between 125 to $2000 \mathrm{~Hz}$, the reverberation time was longer than $4 \mathrm{~s}$. This is a very long RT for this auditorium. Parallel to the RT, the EDT was also very long. However, the difference between the RT and EDT was within the limits of 10\% [10]. In fact, Beranek [10] has shown that EDT measured in an unoccupied hall is an even better indication of acoustic quality than RT. All these measurements were made when the hall was unoccupied as it is very difficult to measure acoustical parameters when the hall is occupied. The RT for the occupied hall was calculated according to the Hidaka et al. [33] method for the known upholstery of the seats, and the results are listed in Table 2. The RT was very long and unacceptable for both occupied and unoccupied conditions.

Although clarity (C80) indicates whether the musical details and the instruments in an orchestra will be heard pleasantly, it is also an indication of speech intelligibility. The average C 80 in the auditorium was within practical limits and very close to the optimum range of -2 to +2 for multipurpose auditoriums. When the hall was empty, the C 80 for frequencies between 125 to $2000 \mathrm{~Hz}$ was approximately $-3 \mathrm{~dB}$; this is lower than the acceptable level. Hidaka et al. [33] have shown that C80 does not change significantly when the audience enters a hall.

Definition (D50) is more related to speech intelligibility than (C80). For all the frequencies, definition (D50) was lower than $0.5 \mathrm{~s}$, thereby indicating inferior speech intelligibility. Another parameter related to speech intelligibility is the Signal-to-Noise Ratio (SNR). When the auditorium was unoccupied, the SNRs for the mid frequencies were more than $10 \mathrm{~dB}$, which is a satisfactory level. SNRs were lower than $10 \mathrm{~dB}$ for low and high frequencies, especially for 31.5, 63, 4000, and $8000 \mathrm{~Hz}$ and higher for the mid frequencies. However, when the auditorium was full with an audience, the background noise increased and SNR fell to an unacceptable level, thereby degrading the speech intelligibility. 
Table 2. Calculated reverberation times of the occupied hall.

\begin{tabular}{ccccccc}
\hline \multicolumn{7}{c}{ Reverberation times of the occupied hall } \\
\hline Frequencies, $\mathrm{Hz}$ & 125 & 250 & 500 & 1000 & 2000 & 4000 \\
\hline $\mathrm{RT}_{\text {occupied, }} \mathrm{s}$ & 3.5 & 3.73 & 3.7 & 3.18 & 3.00 & 2.4 \\
\hline
\end{tabular}

The measurements of STI and RASTI as seen in Table 1 show that, except for points very close to the stage, these speech intelligibility parameters were much degraded.

Normally, side reflectors are used in music auditoria to strengthen the singers' voices. Studies by Barron and Marshall $[13,34,35]$ showed that "lateral reflections give a listener the subjective impression of being enveloped by the sound and they increased the spatial impression". Two recent studies on the subject indicate that lateral reflections are beneficial due to their increasing effect on binaural loudness [36,37]. In speech auditoriums, it is necessary to provide equal loudness all over the hall with side and top reflectors. It is not possible to use special reflective surfaces in this hall, because all the present reflecting surfaces cause an echo, and if side reflectors are used, they will cover the spectator tribunes during the sporting activities.

All these analyses explain the poor quality of acoustics for both music and speech in the hall, which is not helped by the inflexible seating arrangements. Our proposals seek to improve the acoustics within the context of the existing seating layout illustrated in Figure 1.

\subsection{Simulations}

The computer simulation of the hall was performed using the ODEON 14 software package [38]. Twenty receivers were used in total with the sound source at the stage as shown in Figure 3. ODEON 14 is based on sophisticated methods of physical analysis known as the modulation transfer function, image-source method, and ray tracing. With simulation models, it is possible to see the effects of different geometries and the effects of different surface materials on room acoustics. In this study, the authors checked the latter. The first simulation (Simulation No. 1) was conducted for an unoccupied condition. Sound absorption coefficients of all the surfaces used in the simulations are given in Table 3 and the simulation parameters are given in Table 4. This simulation was done in order to find the similarities between the measured and simulated values, for which the just noticeable difference (JND) was used as the unit of measurement. The measured and simulation values of a number of parameters show agreement, especially between 500 to $2000 \mathrm{~Hz}$ frequencies. The small differences observed are due to the assumptions of the sound absorption coefficients of the surfaces in the simulations. Outside this range, there is a significant difference between the measured and simulated values. The next simulation (Simulation No. 2) was made for the occupied hall. The averages of all the twenty points when the hall was occupied and without any treatment are given in Table 5. In the simulations, an attempt was made to use a curtain with a surface density of $0.26 \mathrm{~kg} / \mathrm{m}^{2}$ all over the seating area instead of with an audience, as proposed by Hidaka et al. [33]. In this simulation, the results were not more satisfactory and so the idea was not used.

In Simulation No. 3, the ceiling and walls were covered with acoustic plates. It was decided to glue grey colored, $5 \mathrm{~cm}$ thick fireproof pyramidal melamine plates on the ceiling at the bottom surfaces of the aluminum sandwich panels. Melamine plates are lighter and more durable then polyurethane plates of the same type. On the walls, cream colored melamine plates with fireproof textile on the front surface and an air cavity at the back were added. So, the colors of the ceiling and walls were not changed and the red aluminum space-frame elements were kept visible. These elements would, at the same time, contribute to the diffusion of sound during concerts. The results are given in Table 5 . This treatment provided too much absorption, and the reverberation time was reduced too drastically. Consequently, it was decided to reduce the sound absorbers in the fourth simulation (Simulation No. 4). In the fourth simulation the back wall and all the walls of the side tribunes were kept as they were without any acoustic treatment. Thus, the narrow columns, beams, and the long narrow horizontal 
walls in this area will increase the diffusion of sound, which is a favorable condition during music activities. The results are given in Table 5. This provided better RT and EDT values. In the hall, some curtains were used to cover the glass surfaces and it is also recommended that these curtains be open during the music activities.

Table 3. Sound absorption coefficients of all the surfaces used in the simulations [39].

\begin{tabular}{cccccccccc}
\hline Material & $\mathbf{6 3 ~ H z}$ & $\mathbf{1 2 5} \mathbf{H z}$ & $\mathbf{2 5 0} \mathbf{H z}$ & $\mathbf{5 0 0} \mathbf{H z}$ & $\mathbf{1 ~ k H z}$ & $\mathbf{2} \mathbf{~ k H z}$ & $\mathbf{4} \mathbf{~ k H z}$ & $\mathbf{8} \mathbf{~ k H z}$ \\
\hline Linoleum on concrete & 0.02 & 0.02 & 0.02 & 0.03 & 0.04 & 0.04 & 0.05 & 0.05 \\
Aluminum sandwich panels & 0.00 & 0.00 & 0.00 & 0.00 & 0.00 & 0.00 & 0.00 & 0.00 \\
Glazed tiles & 0.01 & 0.01 & 0.01 & 0.01 & 0.01 & 0.02 & 0.02 & 0.02 \\
Painted plaster surface & 0.02 & 0.02 & 0.02 & 0.02 & 0.02 & 0.02 & 0.02 & 0.02 \\
Double glazing & 0.10 & 0.10 & 0.007 & 0.05 & 0.03 & 0.02 & 0.02 & 0.02 \\
Smooth unpainted concrete & 0.01 & 0.01 & 0.01 & 0.02 & 0.02 & 0.02 & 0.05 & 0.05 \\
Plywood on battens & 0.30 & 0.30 & 0.20 & 0.15 & 0.13 & 0.10 & 0.008 & 0.008 \\
Seated audiences & 0.16 & 0.16 & 0.24 & 0.56 & 0.69 & 0.81 & 0.78 & 0.78 \\
Curtains folded to 7/8 area & 0.03 & 0.03 & 0.12 & 0.15 & 0.27 & 0.37 & 0.42 & 0.42 \\
Acoustical wall panels & 0.40 & 0.40 & 0.80 & 0.95 & 0.80 & 0.90 & 0.95 & 0.95 \\
Acoustical ceiling panels & 0.25 & 0.25 & 0.45 & 0.65 & 0.80 & 0.80 & 0.10 & 1.00 \\
Chair, unoccupied, lightly upholstered & 0.02 & 0.02 & 0.02 & 0.03 & 0.04 & 0.04 & 0.05 & 0.05 \\
Chair, occupied, lightly upholstered & 0.51 & 0.51 & 0.64 & 0.75 & 0.80 & 0.82 & 0.83 & 0.83 \\
\hline
\end{tabular}

Table 4. The simulation parameters used.

\begin{tabular}{cc}
\hline Scattering Method & Lambert \\
\hline Number of rays & 100,000 \\
Max. reflection order & 2000 \\
Impulse response length & $4000 \mathrm{~ms}$ \\
Impulse response resolution & $3.0 \mathrm{~ms}$ \\
Transition order & 2 \\
Number of early scatter rays & 50 \\
Late reflection density & $100 \mathrm{~ms}$ \\
\hline
\end{tabular}

Table 5. Comparison of some measured and simulated parameters of the hall.

\begin{tabular}{lcccccccccc}
\hline FREQUENCIES, Hz & $\mathbf{3 1 . 5}$ & $\mathbf{6 3}$ & $\mathbf{1 2 5}$ & $\mathbf{2 5 0}$ & $\mathbf{5 0 0}$ & $\mathbf{1 0 0 0}$ & $\mathbf{2 0 0 0}$ & $\mathbf{4 0 0 0}$ & $\mathbf{8 0 0 0}$ & $\mathbf{1 6 , 0 0 0}$ \\
\hline EDT [s] Real & 3.6 & 1.4 & 4.1 & 5.0 & 4.7 & 4.1 & 4.2 & 2.9 & 1.8 & 1.0 \\
Simulation 1 & 6.45 & 7.27 & 5.18 & 4.54 & 3.43 & 2.63 & 1.88 & 0.98 & & \\
Simulation 2 & 3.40 & 3.42 & 2.55 & 2.30 & 1.75 & 1.47 & 1.17 & 0.75 & & \\
Simulation 3 & 1.51 & 1.50 & 1.10 & 0.68 & 0.58 & 0.46 & 0.96 & 0.17 & & \\
Simulation 4 & 2.68 & 2.76 & 1.72 & 1.47 & 1.14 & 0.88 & 0.96 & 0.43 & & \\
\hline RT [s] Real & 1.4 & 1.8 & 4.2 & 4.6 & 4.9 & 4.4 & 4.3 & 3.3 & 2.1 & 0.5 \\
Simulation 1 & 5.95 & 6.79 & 5.36 & 4.78 & 3.66 & 2.83 & 2.03 & 1.06 & & \\
Simulation 2 & 4.35 & 4.24 & 3.26 & 2.95 & 2.18 & 1.88 & 1.43 & 0.84 & & \\
Simulation 3 & 2.16 & 2.15 & 1.62 & 1.60 & 1.32 & 0.85 & 1.18 & 0.52 & & \\
Simulation 4 & 3.24 & 3.28 & 2.23 & 1.99 & 1.59 & 1.11 & 1.18 & 0.61 & & \\
\hline C80 [dB] Real & -7.0 & -1.3 & -3.3 & -3.6 & -2.9 & -2.8 & -3.3 & -1.8 & 0.7 & 0.9 \\
Simulation 1 & -4.4 & -5.3 & -3.9 & -3.4 & -2.3 & -0.6 & 1.2 & 5.5 & & \\
Simulation 2 & -1.6 & -1.7 & -0.2 & 0.4 & 1.8 & 2.7 & 4.3 & 8.0 & & \\
Simulation 3 & 2.8 & 2.5 & 6.1 & 9.4 & 9.6 & 12.1 & 7.7 & 18.7 & & \\
Simulation 4 & -0.9 & -1.1 & 1.6 & 2.7 & 3.9 & 5.8 & 5.7 & 10.5 & & \\
\hline D50 [-] Real & 0.25 & 0.4 & 0.3 & 0.2 & 0.2 & 0.3 & 0.2 & 0.3 & 0.4 & 0.6 \\
Simulation 1 & 0.20 & 0.17 & 0.21 & 0.23 & 0.28 & 0.35 & 0.44 & 0.63 & & \\
Simulation 2 & 0.32 & 0.31 & 0.39 & 0.42 & 0.50 & 0.55 & 0.62 & 0.77 & & \\
Simulation 3 & 0.54 & 0.52 & 0.71 & 0.82 & 0.84 & 0.89 & 0.76 & 0.96 & & \\
Simulation 4 & 0.33 & 0.32 & 0.45 & 0.50 & 0.57 & 0.65 & 0.66 & 0.81 & & \\
\hline
\end{tabular}


Table 5. Cont.

\begin{tabular}{|c|c|c|c|c|c|c|c|c|c|c|}
\hline FREQUENCIES, Hz & 31.5 & 63 & 125 & 250 & 500 & 1000 & 2000 & 4000 & 8000 & 16,000 \\
\hline $\mathrm{L}_{\mathrm{f}}[80]$ Real & \multicolumn{10}{|c|}{ Not Measured } \\
\hline Simulation 1 & 0.142 & 0.148 & 0.147 & 0.143 & 0.134 & 0.145 & 0.140 & 0.122 & & \\
\hline Simulation 2 & 0.150 & 0.153 & 0.152 & 0.153 & 0.147 & 0.145 & 0.141 & 0.130 & & \\
\hline Simulation 3 & 0.117 & 0.111 & 0.098 & 0.085 & 0.081 & 0.076 & 0.098 & 0.047 & & \\
\hline Simulation 4 & 0.143 & 0.137 & 0.121 & 0.112 & 0.103 & 0.096 & 0.108 & 0.068 & & \\
\hline STI, Real & \multicolumn{10}{|c|}{ Average $=0.42$} \\
\hline Simulation 1 & \multicolumn{10}{|c|}{ Average $=0.43$} \\
\hline Simulation 2 & \multicolumn{10}{|c|}{ Average $=0.54$} \\
\hline Simulation 3 & \multicolumn{10}{|c|}{ Average $=0.58$} \\
\hline Simulation 4 & \multicolumn{10}{|c|}{ Average $=0.59$} \\
\hline
\end{tabular}

Discussion of the Simulation Results

The discussion below is for the fourth and final simulation. The average reverberation time of the occupied hall for the mid frequencies with the proposed measures was $1.6 \mathrm{~s}$. Thus, the required criteria were met in terms of RT for both speech and music. The average EDT for the mid frequencies was $1.22 \mathrm{~s}$, which is below but very close to the 1.4 to $1.9 \mathrm{~s}$ range. This is due to the absence of side reflectors in this hall. The requirement that EDT should not be more than $10 \%$ lower than RT could also not be met and was $20 \%$ lower.

C80, which is an important parameter for both music and speech, remained between $-1,0$, and $10 \mathrm{~dB}$ for all frequencies. For the mid frequencies, it was approximately 4.0. While these are practical values, it is impossible to provide the ideal values of -2 to $+2 \mathrm{~dB}$. Another speech intelligibility parameter D50 reached the criterion of being above 0.50 except for very low frequencies. STI results after the proposed measures would reach a fair to good level, which is quite reasonable for this kind of problematic hall. LF80 (lateral energy fraction) shows the spatial configuration which fails in all simulations because it should be $>25$ for symphonic music.

By keeping the lower side walls on the tribunes untreated, space was achieved for the portable seating area on the sports field. However, it was not possible to provide this for the tribune seats. In order to provide stage support, removable reflectors made of timber and medium-density fiber boards were proposed for use only during music activities, as seen in Figure 7 . These reflectors will be $2.5 \mathrm{~m}$ wide and $4 \mathrm{~m}$ high.

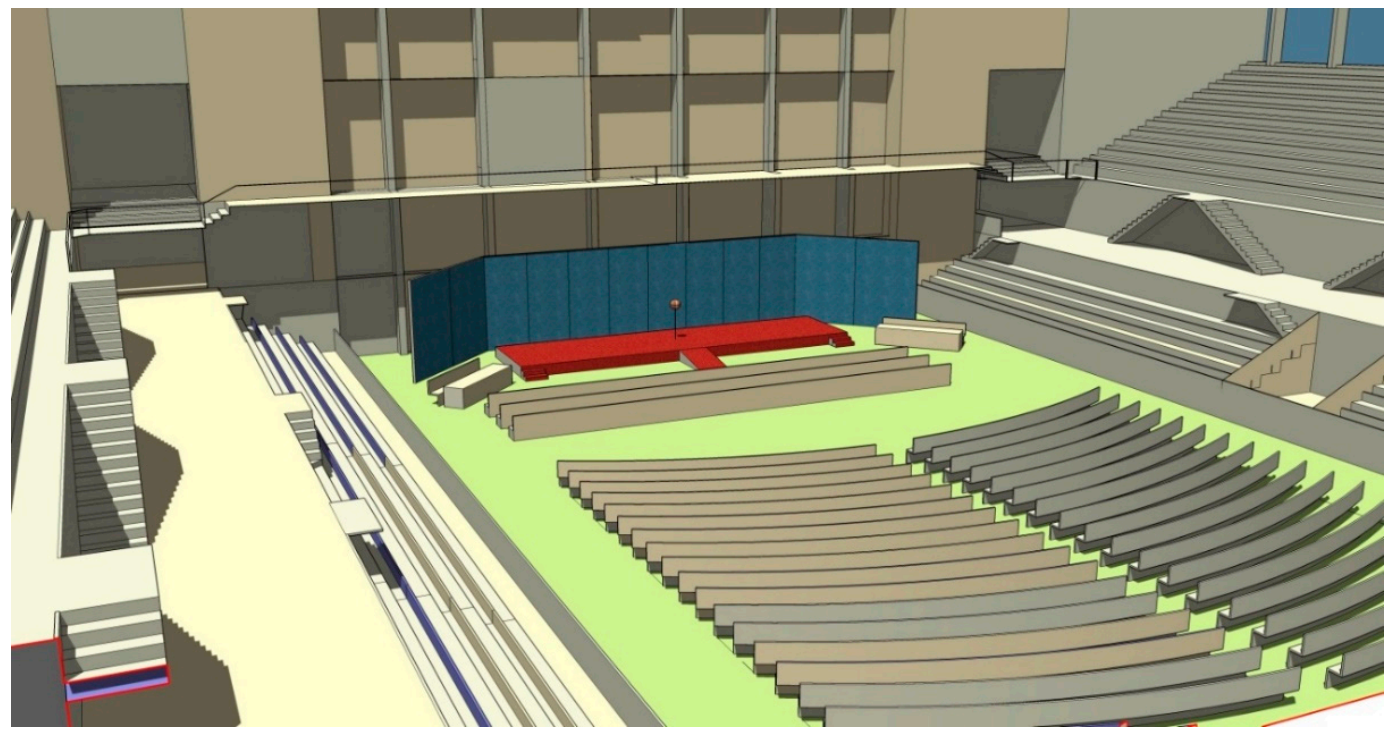

Figure 7. Removable reflectors for the stage support during music activities in the hall. 


\section{Conclusions}

The measurements of the acoustic parameters show the extent of the problems at Lala Mustafa Paşa Hall. The average reverberation time for the mid frequencies reaches up to $5 \mathrm{~s}$ and the other parameters indicate the general failure of the acoustic conditions. The excessive reverberation time does not make the conditions favorable for music and in fact makes the sound blurred. The measurements were made when the hall was unoccupied. For the occupied conditions, both predictive calculations and for some occasions' actual measurements were made. The sound absorbance of the occupants' bodies did not improve the acoustic conditions sufficiently, and in fact, spectator noise increased the background noise level. Average INR and SNR of all the points shown in Figure 5 with the average RT, EDT, C80, and D50 are given in Figure 6.

Simulation studies using ODEON [38] indicated similar results with the measurements of the unoccupied hall. For the level of similarity between the real measurements and simulations, just noticeable difference (JND) was used as the unit of measurement. Furthermore, the next simulations were made for the occupied hall and a number of remedies were tested. The solution of gluing grey colored $5 \mathrm{~cm}$ thick fireproof pyramidal melamine plates on the ceiling at the bottom surfaces of the aluminum sandwich panels and fitting cream colored melamine plates with fireproof textile on the front surface and air cavities at the back proved the best solution. The red aluminum space frame elements of the ceiling were kept as they are without being covered with any acoustic treatment. This contributed to the diffusion of sound during music activities. The back wall and all the walls of the side tribunes were kept as they were without any acoustic treatment. Thus the narrow columns, beams, and the long narrow horizontal walls in this area will increase the diffusion of sound, which is a favorable condition during music activities as well.

It was not possible to use side reflectors in this hall. However, portable reflectors for the stage were proposed in order to provide a stage support factor for the orchestra on the stage.

All the measures were taken according to one seating arrangement, shown in Figure 1. It is not possible to achieve favorable conditions with these measures for other seating arrangements. When the university completes the proposed measures, new measurements will be made and the results will be discussed in another article.

It can be seen in Table 1 and Figure 3 for speech intelligibility that STI female and STI male are minimum 0.35 (poor) and maximum 0.49 (fair) for both female and male except point A9 which is fair for STI female but poor for STI male. RASTI is always poor that with a minimum 0.33 and maximum 0.43 for all points.

Reverberation time of the occupied hall was minimum 2.4 and maximum 3.73, which can be seen in Table 2. In addition, reverberation time for real measurements was minimum 0.5 and maximum 4.9. Reverberation time for Simulation No. 1 was minimum 1.06 and maximum 6.79, which shows no difference between measured and simulated values. Reverberation time for Simulation No. 2 was minimum 0.84 and maximum 4.35 with the addition of curtains $\left(0.26 \mathrm{~kg} / \mathrm{m}^{2}\right)$ for windows over the seating area. Reverberation time for Simulation No. 3 was minimum 0.52 and maximum 2.16 with the addition of acoustic plates on the ceiling and walls. Reverberation time for Simulation No. 4 was minimum 0.61 and maximum 3.28 by keeping the back wall and all of the walls as they are for increasing the diffusion of sound, which is favorable for music performances.

Author Contributions: H.Z.A. and M.B.O. conceived and designed the concept and outline for the article, performed the experiments, simulations, and wrote the manuscript.

Funding: This research received no external funding.

Conflicts of Interest: The authors declare no conflict of interest. 


\section{References}

1. Cairoli, M. Architectural customized design for variable acoustics in a multipurpose auditorium. Appl. Acoust. 2018, 140, 167-177. [CrossRef]

2. Kulowski, A. The caustic in the acoustics of historic interiors. Appl. Acoust. 2018, 133, 82-90. [CrossRef]

3. Long, M. Architectural Acoustics, 2nd ed.; Academic Press: California, USA, 2014.

4. Barron, M.; Kissner, S. A possible acoustic design approach for multi-purpose auditoria suitable for both speech and music. Appl. Acoust. 2017, 115, 42-49. [CrossRef]

5. Michel, H.; Myers, J. Increasing liveness and clarity in a multipurpose civic center. J. Acoust. Soc. Am. 2016, 140, 3294. [CrossRef]

6. Sakamoto, S.; Cui, Z.; Miyashita, T.; Morimoto, M.; Suzuki, Y.; Sato, H. Effects of inter-word pauses on speech intelligibility under long-path echo conditions. Appl. Acoust. 2018, 140, 263-274. [CrossRef]

7. Brunskog, J.; Gade, A.C.; Bellester, G.P.; Calbo, L.R. Increase in voice level and speaker comfort in lecture rooms. J. Acoust. Soc. Am. 2009, 125, 2072-2082. [CrossRef] [PubMed]

8. Eldakdoky, S.; Elkhateeb, A. Acoustic improvement on two lecture auditoria: Simulation and experiment. Front. Archit. Res. 2017, 6, 1-16. [CrossRef]

9. Beranek, L.L. Subjective rank-orderings and acoustical measurements for fifty-eight concert halls. Acta Acust. United Acust. 2003, 89, 494-508.

10. Beranek, L.L. Concert hall acoustics-2008. J. Audio Eng. Soc. 2008, 56, 532-544.

11. Hyde, J. Acoustical intimacy in concert halls: Does visual input affect the aural experience? In Proceedings of the Institute of Acoustics, Auditorium Acoustics: Historical and Contemporary Design and Performance, London, UK, 19-21 July 2002.

12. Kwon, Y.; Siebein, G.W. Chronological analysis of architectural and acoustical indices in music performance halls. J. Acoust. Soc. Am. 2007, 121, 2691-2699. [CrossRef] [PubMed]

13. Marshall, A.H. Acoustical design and evaluation of Christchurch Town Hall, New Zealand. J. Acoust. Soc. Am. 1979, 65, 951-957. [CrossRef]

14. Sü, Z.; Yilmazer, S. The acoustical performance analysis of Bilkent amphitheater: Proposal for acoustical renovation. Archit. Sci. Rev. 2006, 49, 167-178. [CrossRef]

15. Lautenbach, M.R.; Vercammen, M.L.S.; Lorenz-Kierakiewitz, K.-H. Renovation of the concert hall De Doelen, Rotterdam, The Netherlands. Early Reflections Strength and Stage Acoustics. In Proceedings of Institute of Acoustics; Part 3; Institute of Acoustics: Oslo, Norway, 3-5 October 2008; p. 30.

16. Leccese, F.; Rocca, M.; Salvadori, G. Fast estimation of speech transmission index using the reverberation time: Comparison between predictive equations for educational rooms of different sizes. Appl. Acoust. 2018, 140, 143-149. [CrossRef]

17. Sala, E.; Rantala, L. Acoustics and activity noise in school classrooms in Finland. Appl. Acoust. 2016, 114, 252-259. [CrossRef]

18. John, J.; Thampuran, A.L.; Premlet, B. Objective and subjective evaluation of acoustic comfort in classrooms: A comparative investigation of vernacular and modern school classroom in Kerala. Appl. Acoust. 2016, 104, 33-41. [CrossRef]

19. Zhang, J.; Xiao, X.; Sheng, X.; Zhang, C.; Wang, R.; Jin, X. SEA and conribution analysis for interior noise of a high speed train. Appl. Acoust. 2016, 112, 158-170. [CrossRef]

20. Brüel \& Kjaer. DIRAC Room Acoustics Software-Type 7841; Brüel \& Kjaer: Narum, Denmark, 2011.

21. International Organization for Standardization (ISO). Standard 3382-1. In Acoustics-Measurement of Room Acoustic Parameters-Part 1: Performance Spaces; The International Organization for Standardization (ISO): Geneva, Switzerland, 2009.

22. The British Standards Institution. Sound System Equipment_Part 16: Objective Rating of Speech Intelligibility by Speech Transmission Index; BS EN 60268-16; European Committee for Electrotechnical Standardization: Brussels, Belgium, 2011.

23. Kuttruff, H. Room Acoustics, 6th ed.; CRC Press: Germany, 2016.

24. Hidaka, T.; Beranek, L.L.; Masuda, S.; Nishihara, N.; Okano, T. Acoustical design of the Tokyo Opera City (TOC) concert hall, Japan. J. Acoust. Soc. Am. 2000, 107, 340-354. [CrossRef]

25. Ando, Y. Auditory and Visual Sensations; Springer: New York, NY, USA, 2010. 
26. Barron, M.; Marshall, A.H. Spatial impression due to early lateral reflections in concert halls: The derivation of a physical measure. J. Sound Vib. 1981, 77, 211-232. [CrossRef]

27. Szokolay, S.V. Environmental Science Handbook for Architects and Builders; Construction Press: New York, NY, USA, 1980.

28. Callender, J.H.; Crosbie, M.J. (Eds.) Time-Saver Standards for Architectural Design Data; McGraw-Hill: New York, NY, USA, 1974; pp. 696-719.

29. Barron, M. Auditorium Acoustics and Architectural Design, 2nd ed.; Spon Press: London, UK, 2010.

30. Bradley, J.S. Acoustical comparison of three theaters. J. Acoust. Soc. Am. 1986, 79, 1827-1832. [CrossRef] [PubMed]

31. Howard, D.M.; Angus, J. Acoustics and Psychoacoustics, 4th ed.; Focal Press: Oxford, UK, 2009.

32. Bradley, J.S.; Soulodre, G.A.; Norcross, S. Factors influencing the perception of bass. In Proceedings of the 133rd Meeting Lay Language Papers for Acoustical Society of America/NOISE-CON 97, State College, PA, USA, 17 June 1997.

33. Hidaka, T.; Nishihara, N.; Beranek, L.L. Relation of acoustical parameters with and without audiences in concert halls and a simple method for simulating the occupied state. J. Acoust. Soc. Am. 2001, 109, 1028-1042. [CrossRef] [PubMed]

34. Barron, M. The subjective effects of first reflections in concert halls-The need for lateral reflections. J. Sound Vib. 1971, 15, 475-494. [CrossRef]

35. Marshall, A.H.; Barron, M. Spatial responsiveness in concert halls and the origins of spatial impression. Appl. Acoust. 2001, 62, 91-108. [CrossRef]

36. Lokki, T.; Pätynen, J.; Tervo, S.; Siltanen, S.; Savioja, L. Engaging concert hall acoustics is made up of temporal envelope preserving reflections. J. Acoust. Soc. Am. 2011, 129, EL223. [CrossRef] [PubMed]

37. Lokki, T.; Pätynen, J. Lateral reflections are favorable in concert halls due to binaural loudness. J. Acoust. Soc. Am. 2011, 130, EL345. [CrossRef] [PubMed]

38. Odeon A/S. ODEON Room Acoustics Software, User's Manual, Version 14; Odeon A/S: Lyngby, Denmark, 2018.

39. Absorption Coefficients. Available online: www.acoustic.ua/st/web_absorption_data_eng.pdf (accessed on 10 February 2019).

(C) 2019 by the authors. Licensee MDPI, Basel, Switzerland. This article is an open access article distributed under the terms and conditions of the Creative Commons Attribution (CC BY) license (http://creativecommons.org/licenses/by/4.0/). 